\title{
Vision impairment and older drivers: who's driving?
}

\author{
J E Keeffe, C F Jin, L M Weih, C A McCarty, H R Taylor
}

Br J Ophthalmol 2002;86:1118-1121

Aim: To establish the association between impaired vision and drivers' decisions to stop driving, voluntarily restrict driving, and motor vehicle accidents.

Methods: Driving related questions were included in a population based study that determined the prevalence and incidence of eye disease. Stratified random cluster samples based on census collector districts were selected from the Melbourne Statistical Division. Eligible participants aged 44 years and over were interviewed and underwent a comprehensive ophthalmic examination. The outcomes of interest were the decision to stop driving, limiting driving in specified conditions, and driving accidents. The associations between these outcomes and the legally prescribed visual acuity $(<6 / 12)$ for a driver's licence were investigated.

Results: The mean age of the 2594/3040 (85\%) eligible participants was 62.5 (range 44-101). People with visual acuity less than $6 / 12$ were no more likely to have an accident than those with better vision $\left(\chi^{2}=0.175, p>0.9\right)$. Older drivers with impaired vision, more so than younger adults, restrict their driving in visually demanding situations $(p<0.05)$. Of the current drivers, $2.6 \%$ have vision less than that required to obtain a driver's licence. The risk of having an accident increased with distance driven $(O R$ 2.57, $\mathrm{CL} 1.63,4.04$ for distance $>31000 \mathrm{~km}$ ) but not with age.

Conclusion: There was no greater likelihood of self reported driving accidents for drivers with impaired vision than those with good vision. While many older drivers with impaired vision limit their driving in adverse conditions and some drivers with impaired vision stop driving, there are a significant number of current drivers with impaired vision.

v $\mathrm{n}$ the age group 80 years and over, one in three people have vision less than the legally required driving standard. ${ }^{1}$ It is projected that, by the year 2051, there will be at least double the number of elderly people ${ }^{2}$ and thereby an increase in the number of people with impaired vision. This could have significant road safety implications.

Vision testing, often only visual acuity, is a required procedure to obtain a driver's licence. There is no agreed standard within or between countries, however, on the level of visual acuity required for driving. The first vision standard for driving involved the reading of the letters or numbers on a number plate at a specified distance. ${ }^{3}$ From this, licensing authorities have arbitrarily set a minimum standard to obtain a full or restricted licence for both visual acuity. In Australia the visual acuity required for issue or renewal of a driver's licence is either 6/12 or 6/18 depending on the state of issue. ${ }^{4}$ In the United States, visual acuity of $6 / 12$ is the most common standard but ranges up to 6/21 for an unrestricted licence. ${ }^{5}$ The current requirement in the United Kingdom is to be able to read the equivalent of 3.125" letters from 67 feet which was thought to convert to a Snellen acuity of approximately 6/15 but has recently been shown to more closely approximate $6 / 10 .^{3}$

There is conflicting evidence of the effects of vision impairment on driving. Retrospective studies have investigated the link between impaired vision (visual acuity 6/12 or 6/15) and driving accident records. ${ }^{67}$ Only weak links were found between visual acuity and the likelihood of accidents for those with lower visual acuity. Reduced visual acuity (categories including up to <6/15) were found to be not significantly related to at-fault crashes in cataract patients but reduced contrast sensitivity did elevate the risk of crash involvement. ${ }^{8}$

The purpose of this study was to examine the association between vision impairment as measured by visual acuity and the decision to restrict or stop driving and motor vehicle accidents in a representative cohort of urban Australians.

\section{METHODS}

The Melbourne Visual Impairment Project (VIP) was a population based study of Melbourne adults. The detailed methodology has been published previously. ${ }^{9}$ Briefly, nine pairs of census collector districts were randomly selected from the Melbourne Statistical Division for the baseline study. Eligible residents were defined as people aged 40 years and older and who had been resident in their homes for at least 6 months. From the household census demographic information was collected from the eligible residents who were then invited to local examination centres for a standard ophthalmic examination and completion of an extensive eye health related questionnaire. The protocol was approved by the human research and ethics committee of the Royal Victorian Eye and Ear Hospital.

Letters were sent to all 3271 participants from the baseline study inviting participation in the 5 year follow up study. The standard ophthalmic examination included measurement of presenting (usual or "walking around") visual acuity (VA) and, for all those with vision less than $6 / 6$, best corrected VA was measured after refraction.

Participants were asked if they had ever driven a motor vehicle and if they were current drivers. Current drivers were asked about their accident record in the intervening 5 years since the baseline study. To determine the amount of driving each year, participants were asked "approximately how many kilometres do you drive each year?" They were also asked if they had deliberately avoided driving in a number of different conditions - at night, in bad weather, during peak hours, in the city centre, over long distances, or in other situations. Those who had stopped driving were asked the reason for doing so as an open ended question with the responses later grouped and coded according to vision or other reasons such as other illness or accident.

Vision impairment in this study was defined and visual acuity $<6 / 12$. This is the most common visual acuity criterion to obtain a driver's licence and is also the level of impairment found in population based studies to be related to an increase in falls and increased social isolation. ${ }^{111}$

Interview data were entered directly into a Paradox database with inbuilt consistency checks. All other data were 
Table 1 Relation between accidents and normal and impaired vision. $\left(\chi^{2}=0.175,2 \mathrm{df}, p>0.9\right)$

\begin{tabular}{lccr}
\hline $\begin{array}{l}\text { Visual } \\
\text { acuity }\end{array}$ & $\begin{array}{l}\text { Accidents due to } \\
\text { impaired vision } \\
(\%)\end{array}$ & $\begin{array}{l}\text { Accidents not } \\
\text { due to impaired } \\
\text { vision (\%) }\end{array}$ & $\begin{array}{l}\text { No accidents } \\
(\%)\end{array}$ \\
\hline$\geqslant 6 / 12$ & $31(1.8)$ & $300(17)$ & $1394(81)$ \\
$<6 / 12$ & $1(2.1)$ & $7(15)$ & $38(83)$ \\
\hline
\end{tabular}

entered twice and verified. Statistical analyses were conducted with sas version 6.0. $\chi^{2}$ Analyses were used to examine the relation between categorical variables and driving behaviour. A p value of less than 0.05 was considered to be statistically significant. Multivariate logistic regression analysis was used to investigate the risks of accidents.

\section{RESULTS}

Of the 3271 participants in the baseline VIP, 231 (7.1\%) had died leaving 3040 eligible to return. From the remaining eligible baseline participants 2594 (85\%) did participate, 51 (2\%) had moved interstate or overseas, 83 (3\%) could not be traced, and $312(10 \%)$ refused to participate. The time between the baseline and follow up examinations ranged between 4 and 7 years (mean 4.5 (SD 0.64), median 4 years). The mean age of the participants was 62.5 years (SD 10.9, range 44-101) and $55 \%$ (1421) were female.

Eligible participants and non-participants were compared for any differences on demographic data available. ${ }^{12}$ The only differences were that people who were born in Greece or Malta and non-English speakers were significantly less likely to participate. All age groups had participation rates of at least $80 \%$ but in the multivariate model participation rate by age only just reached statistical significance $(p=0.04)$. Nonparticipants could not be questioned to establish their driving and accident record.

Driving and ophthalmic data were obtained from 2308 (89\%) participants. Eighty four per cent (1949/2308) reported ever having driven and, of those, 1787 (92\%) were current drivers.

In the previous 5 years, $339(19 \%)$ of the current drivers reported at least one motor vehicle accident. The majority $(86 \%)$ had been involved in one accident with $12 \%$ having two accidents and the remaining $2.4 \%$ reporting three to five accidents. From the 339 who had accidents 32/339 (9.5\%) reported that the accidents were related to vision. People with impaired vision $(<6 / 12)$ were no more likely to have an accident or to attribute that the accident was the result of impaired vision (Table 1 ).

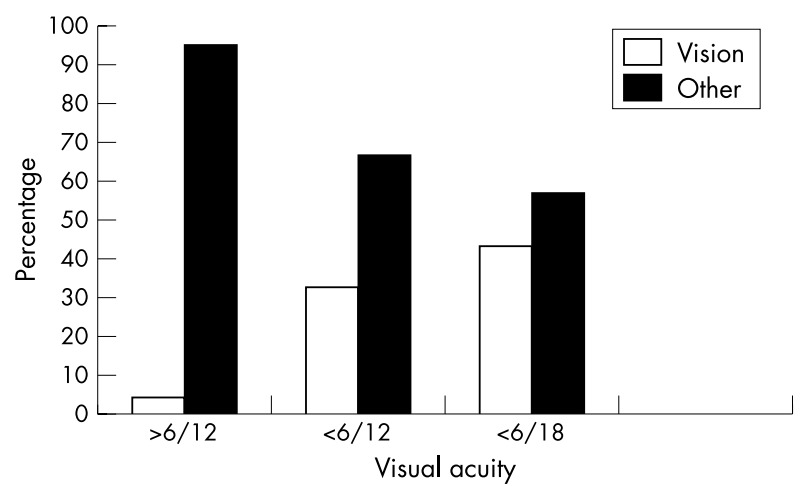

Figure 1 Reasons given for stopping driving by past drivers according to their presenting visual acuity. The differences between the categories of visual acuity are significant, $\chi^{2}=27.56,1 \mathrm{df}$, $\mathrm{p}<0.001)$.

\begin{tabular}{|c|c|c|}
\hline & 44-64 years & $\geqslant 65$ years \\
\hline Conditions & $\%$ & $\%$ \\
\hline Night & 1.8 & $9.5^{* *}$ \\
\hline Peak hour & 2 & 11 * \\
\hline City & 1.6 & $12^{*}$ \\
\hline Bad weather & 0.3 & $1.3 \mathrm{NS}$ \\
\hline Restrict distance & 4.6 & $8.7 \mathrm{NS}$ \\
\hline
\end{tabular}

Those who had stopped driving were asked the reasons why. Eleven per cent (17/160) gave impaired vision as the reason for having stopped driving, while among the other reasons, 19\% did so because of other illness and $9.4 \%$ said that they stopped because they had had an accident. People with impaired vision were more likely to give impaired vision as the reason for stopping driving (Fig 1). The proportion increased as vision impairment worsened (Mantel-Haenszel $\chi^{2}=16.7, \mathrm{l} \mathrm{df}$, $\mathrm{p}<0.001)$. The proportion increased from $4.6 \%$ giving vision as the reason if VA was $6 / 12$ or better to $33 \%$ with VA $<6 / 12$ and $43 \%$ with VA $<6 / 18$.

Some drivers reported restricting their driving in possible adverse driving conditions such as at night time, during peak (rush) hour, in the city area, during bad weather, and limiting the distance driven. Of those who reported limiting their driving in these conditions, $57 \%$ said that they did so because of their vision.

Older drivers with impaired vision were significantly more likely than similarly impaired younger drivers to restrict their driving at night time, during peak hour, or not driving in the city area (Table 2). There were no significant differences for either older or younger adults in restricting driving during bad weather or restricting the distance travelled.

Of those who were current drivers, $2.6 \%$ had vision less than the legal visual acuity limit. The majority had vision worse than $6 / 12$ but equal to or better than 6/18. Thirteen per cent $(6 / 46)$ had VA $<6 / 18$. The main cause of the impaired vision was refractive error (Table 3 ).

In this population aged 44 and older, the greatest proportion $(35 \%)$ of accidents reported were in the age group 50-69 but the younger age groups drove greater distances each year than the older drivers (Table 4).

Logistic regression was conducted to determine if age or distance driven were independently related to accidents. Owing to the small numbers of people in the older age groups, the groups 70-79 years and those 80 and older were combined. There was no significant increase in odds of having an accident with increasing age (Table 5). As the distance driven increased so did the odds of having an accident. The odds of having an accident were almost double if distance driven was between $21000 \mathrm{~km}$ and $30000 \mathrm{~km}$, and if the distance was in excess of $30000 \mathrm{~km}$ the odds were 2.5 times higher than if the distance driven was less than $10000 \mathrm{~km}$ (Table 5).

Table 3 Causes of vision impairment $(<6 / 12)$ in current drivers $(n=46)$

\begin{tabular}{lc}
\hline Cause & No (\%) \\
\hline Refractive error & $37(80)$ \\
Cataract & $3(7)$ \\
Retina (including AMD) & $2(4)$ \\
Other & $4(9)$ \\
\hline
\end{tabular}


Table 4 Analysis of proportion of accidents according to age groups and distances driven

\begin{tabular}{|c|c|c|c|c|c|}
\hline Age group (years) & $\begin{array}{l}<10000 \mathrm{~km} \\
(\%)\end{array}$ & $\begin{array}{l}11000- \\
20000 \mathrm{~km}(\%)\end{array}$ & $\begin{array}{l}21000- \\
30000 \mathrm{~km}(\%)\end{array}$ & $>31000$ (\%) & $\begin{array}{l}\% \text { for each } \\
\text { age group }\end{array}$ \\
\hline$<49$ & 39 & 23 & 19 & 19 & 18 \\
\hline $50-59$ & 39 & 36 & 10 & 15 & 35 \\
\hline $60-69$ & 52 & 30 & 11 & 6 & 28 \\
\hline 70-79 & 75 & 21 & 4 & 0 & 16 \\
\hline$>80$ & 100 & 0 & 0 & 0 & 3 \\
\hline$\%$ according to distance & 50 & 29 & 11 & 10 & 100 \\
\hline
\end{tabular}

$\begin{aligned} & \text { Table } 5 \text { Odds of reporting an accident according to } \\
& \text { age (controlling for distance driven) and distance } \\
& \text { driven (controlling for age) }\end{aligned}$
\begin{tabular}{lll}
\hline Variables & Odds ratio & Confidence limits \\
\hline Age (years) & 1.00 & \\
$\quad$ Reference $<49$ & 0.89 & 0.62 to 1.26 \\
$50-59$ & 0.85 & 0.59 to 1.23 \\
$60-60$ & 1.04 & 0.69 to 1.57 \\
$>70$ & 1.00 & \\
Annual distance driven (km) & \\
Reference $<10000$ & 1.31 & 0.99 to 1.73 \\
$11000-20000$ & 1.82 & 1.20 to 2.76 \\
$21000-30000$ & 2.57 & 1.63 to 4.04 \\
$>31000$ &
\end{tabular}

\section{DISCUSSION}

Some people with impaired vision either stop driving voluntarily or when advised to do so while others do not. This was demonstrated in a survey in Brisbane in 1991 that found that $8 \%$ of people who held drivers' licences had less than the vision required to do so. ${ }^{13}$ A similar survey in the United Kingdom found that $14 \%$ of drivers had vision below the required limit and that more than half had ignored the advice to stop driving. ${ }^{14}$ This Victorian study confirmed that there are people who report that they are current drivers with vision lower than that legally required. The figures for Melbourne could be lower than in other cities and especially in rural areas as Melbourne is relatively well served with public transport, thus offering the choice of not driving to older people.

While we found a small proportion $(2.6 \%)$ of people with impaired vision are current drivers, the numbers become significant when applied to a town or city. For example, in a city with a population 135000 people of whom 55000 (40\%) are aged 45 and over, there could be approximately 1430 drivers on the roads with vision lower than the visual acuity criterion for driving.

Older drivers generally drove shorter annual distances and limited their driving in demanding or adverse conditions. This was especially so of older drivers with impaired vision. These Australian drivers avoided potentially challenging situations as did older drivers in the United States. ${ }^{15}$ Another Australian population based study of older people found similar reasons for stopping driving; in order of importance they were loss of confidence, medical conditions, failing eyesight, no need to continue driving, an accident, or loss of licence. ${ }^{16}$ In addition to identifying factors, Marottoli and colleagues found that it was the combination of factors and that the more factors present, the higher the percentage who stopped driving. ${ }^{17}$

It was the distance driven - that is, exposure on the road, that was independently related to an increased risk of accidents. When controlling for distance driven, older drivers were not more likely to report being involved in road accidents than younger adults. These results are at odds with other studies that have found older drivers to be overinvolved in collisions. ${ }^{18}$
One of the possible reasons for differences found in the risk factors for vehicle accidents and the relation between vision (visual acuity in particular) and accidents is in the methodologies used. Driving behaviour can be observed either on the road with simulated vision impairment ${ }^{19}$ or in driving simulators with people who are vision impaired.$^{20}$ While driving behaviour can be observed that might put a driver at risk and "crashes" occur in the simulator, these findings do not necessarily prove the link between impaired vision and driving accidents. In other studies, patients are recruited from clinics and the vision characteristics of those who are involved in crashes are compared with those that have not been so involved. ${ }^{8}$

The use of a retrospective case-control study inside a population based study on causes and prevalence of vision provided the opportunity to examine the relative risks of driving accidents, the association of impaired vision and driving, and reasons for stopping driving. Population based studies have relatively few people who have significant vision impairment but allow generalisations to be made to the whole of the population represented. Conversely, clinic based studies can recruit large numbers of people who are vision impaired to investigate details related to their driving behaviour and vision.

One of the limitations of this study was that it relied on self report of accidents that has previously been found to have a moderate level of agreement with state recorded crashes. ${ }^{18}$

Almost $20 \%$ of the participants in the VIP had at least one motor vehicle accident in the 5 year period between the baseline and follow up study. In this case-controlled study comparing those with impaired vision with a matched cohort without impaired vision, no relation was found between road accidents and drivers with impaired vision as defined by visual acuity less than 6/12. Given the importance of vision for driving, there must be a cut-off point in vision at which drivers are more likely to have accidents. The evidence from this study does not support the criterion of visual acuity of less than $6 / 12$ as the critical limit. The fact that impaired vision affects driving performance has been demonstrated. ${ }^{14}{ }^{15}$ What those studies and the VIP were not able to determine is what level of visual acuity is required for safe driving (avoidance of crashes).

People with impaired vision might be reluctant to seek an eye examination if they fear that the result of the examination could be the recommendation of the loss of their driver's licence. Rather, people who suspect that they have impaired vision should be encouraged to seek an eye examination as the most common causes of impaired vision in Australians ${ }^{21}$ are either correctable or treatable. Undercorrected refractive error is responsible for about half (53\%) of the impaired "walking or driving around" vision of Australians. Most with visual acuity less than 6/12 can have vision corrected to better than 6/12 with glasses or other corrective techniques. ${ }^{22}$

The majority of participants with vision less than that required to hold a driver's licence was in the category of less than $6 / 12$ but equal to or better than $6 / 18$ and was caused by refractive error. The definition of refractive error in the VIP was a refractive error that could be corrected by one line of 
visual acuity or more. Thus, most of those ineligible on vision grounds need not be if they had an eye examination and prescription of appropriate spectacles. This is a message that needs to be promoted to improve the eye health of Australians.

Cataract was also a cause of impaired vision among current drivers. This need not be so as cataract surgery is successful in restoring visual acuity to better than $6 / 12$ in almost all cases. ${ }^{23}$

Those with vision loss caused by age related macular degeneration (AMD) need to be monitored with regard to driving. In most cases there is no treatment that can reverse the vision loss or retain vision and in almost all cases vision will deteriorate.

\section{CONCLUSION}

The inability to see clearly and detect objects has obvious consequences for driving. There is still no convincing evidence of the exact level of visual acuity at which driving becomes unsafe-that is, is related to an increased risk of accidents. Research is needed to determine the level of visual acuity at which drivers are no longer safe. Our study has shown that less than 6/12 might not be the critical level of visual acuity that is related to road crashes. Some other, presumably lower, visual acuity level might be the criterion used to determine the eligibility to obtain a driver's licence.

This study has demonstrated that there are many Australians driving with vision lower than that required by law. Most of those drivers could have vision improved or restored so that they could meet the required standard.

\section{ACKNOWLEDGEMENTS}

Funding sources include the National Health and Medical Research Council, VicHealth, Jack Brockhoff Foundation, Vision Australia Foundation, Ansell Ophthalmology Foundation, and the Dorothy Edols Estate. Associate professor Cathy McCarty held the Wagstaff fellowship in ophthalmology.

\section{Authors' affiliations}

J E Keeffe, C F Jin, H R Taylor, Centre for Eye Research Australia, University of Melbourne, Melbourne, Australia

L M Weih, Peter MacCallum Research Institute, Melbourne, Australia C A McCarty, Marshfield Epidemiology Research Center, Marshfield, WI, USA

Correspondence to: Jill Keeffe, PhD, Centre for Eye Research Australia Royal Victorian Eye and Ear Hospital, Locked Bag 8, East Melbourne, Vic 8002, Australia; jillek@unimelb.edu.au

Accepted for publication 11 April 2002

\section{REFERENCES}

1 Taylor HR, Livingston PM, Stanislavsky YL, et al. Visual impairment in Australia: distance visual acuity, near vision and visual field findings of the Melbourne Visual Impairment Project. Am J Ophthalmol 1997; 123:328-37.

2 Australian Bureau of Statistics. Population projections, 1997-2051. Catalogue no 3222.0. Canberra: Australian Government Printing Service, 1998.

3 Drasdo N, Haggerty CM. A comparison of the British number plate and Snellen vision tests for car drivers. Ophthal Physiol Opt 1981;1:39-54.

4 Austroads guidelines for health professionals and their obligations. Assessing fitness to drive. Sydney: Austroads, 1998

5 Fishbaugh J. Look who's driving now-visual standards for driver licensing in the United States. Insight 1995;XX:11-19.

6 Gresset JA, Meyer FM. Risk of accidents among elderly drivers with visual acuity equal to $6 / 12$ or $6 / 15$ and lack of binocular vision. Ophthalmol Physiol Opt 1994;14:33-7.

7 McCloskey LW, Koepsell TD, Wolf ME, et al. Motor vehicle collision injuries and sensory impairment of older drivers. Age Ageing 1994:23:267-73.

8 Owsley C, Stalvey BT, Wells J, et al. Visual risk factors for crash involvement in older drivers with cataract. Arch Ophthalmol 2001:119:881-7.

9 Livingston PM, Carson CA, Stanislavsky YL, et al. Methods for a population-based study of eye disease: the Melbourne Visual Impairment Project. Ophthalmic Epi 1994;1:139-48.

10 Ivers RQ, Cummin RG, Mitchell P, et al. Visual impairment and falls in older adults: the Blue Mountains eye study. J Am Geriatr Soc 1998;46:58-64.

11 Rubin GS, Bandeen-Roche IK, Huang GH, et al. The association of multiple visual impairments with self-reported disability: SEE project. Invest Ophthalmol Vis Sci 2001;42:64-72.

12 McCarty CA, Nanjan BM, Taylor HR. Vision impairment predicts 5 year mortality. Br J Ophthalmol 2001;85:322-6.

13 McConnell RA, Spall AD, Hirst LW, et al. A survey of the visual acuity of Brisbane drivers. Med J Aust 1991;155:107-11.

14 Hall N, Sayer AA, Evans J, et al. Visual acuity and its relationship to early growth, eye disease, and aging in North Hertfordshire. Ophthalmic Epidemiol 1998;5:83-90

15 Ball K, Owsley C, Stalvey B, et al. Driving avoidance and functional impairment in older drivers. Acc Anal Prev 1998;30:313-22.

16 Stacey B, Kendig H. Driving, cessation of driving, and transport safety issues among older people. Health Promotion J Aust 1997;7:175-9.

17 Marottoli RA, Ostfeld AM, Merrill SS, et al. Driving cessation and changes in mileage driven among elderly individuals. J Gerontol 1993:48:S255-60.

18 McGwin G Jr, Owsley C, Ball K. Identifying crash involvement among older drivers: agreement between self-report and state records. Acc Anal Prev 1998;30:781-91.

19 Wood JM, Troutbeck R. Effect of visual impairment on driving. Human Factors 1994; $36: 476-87$

20 Szlyk JP, Pizzimenti CE, Fishman GA, et al. A comparison of driving in older subjects with and without age-related macular degeneration. Arch Ophthalmol 1995;113:1033-40.

21 Weih LM, van Newkirk M, McCarty CA, et al. Age-specific causes of bilateral visual impairment. Arch Ophthalmol 2000;118:264-9.

22 Liou H-L, McCarty CA, Jin CL, et al. Prevalence and predictors of undercorrected refractive errors in the Victorian population. Am J Ophthalmol 1999;127:590-6.

23 Taylor HR. Cataract surgery: how much surgery do we have to do? $\mathrm{Br} J$ Ophthalmol 2000;84:1-2. 